\title{
Assessment of balance in mild and moderate stages of Alzheimer's disease Implications on falls and functional capacity
}

\author{
Eliane Mayumi Kato-Narita' ${ }^{1}$ Ricardo Nitrini ${ }^{2}$, Marcia Radanovic ${ }^{3}$
}

\begin{abstract}
Objective: To analyze the correlation between balance, falls and loss of functional capacity in mild and moderate Alzheimer's disease(AD). Method: 40 subjects without cognitive impairment (control group) and 48 AD patients ( 25 mild, 23 moderate) were evaluated with the Berg Balance Scale (BBS) and the Disability Assessment for Dementia (DAD). Subjects answered a questionnaire about falls occurrence in the last twelve months. Results: Moderate AD patients showed poorer balance $(p=0.001)$ and functional capacity ( $p<0.0001)$ and it was observed a correlation between falls and balance $(r=-0.613$; $p=0.045$ ). Conclusion: There is a decline of balance related to AD which is a factor associated to the occurrence of falls, albeit not the most relevant one. The loss of functional capacity is associated with the disease's progress but not to a higher occurrence of falls. The balance impairment did not correlate with functional decline in AD patients. Key words: Alzheimer's disease, balance, falls, functional capacity, elderly.
\end{abstract}

\section{Avaliação do equilíbrio na doença de Alzheimer leve e moderada: implicações na capacidade funcional e na ocorrência de quedas}

\section{RESUMO}

Objetivo: Analisar a correlação entre déficit de equilíbrio, ocorrência de quedas e prejuízo funcional na doença de Alzheimer (DA). Método: 40 idosos sem comprometimento cognitivo (grupo controle) e 48 idosos com DA (25 leves e 23 moderados), avaliados através da Escala de Equilíbrio de Berg (EEB) e Escala de Avaliação de Incapacidade (EAl), e questionados quanto à ocorrência de quedas nos últimos doze meses. Resultados: $O$ equilíbrio no grupo DA moderada foi pior do que no grupo leve $(p=0,001)$, bem como a capacidade funcional $(p<0,0001)$, sem diferença na ocorrência de quedas entre os grupos. Na DA moderada, houve correlação entre ocorrência de quedas e EEB ( $r=-0,613$; $p=0,045)$. Conclusão: Há um declínio do equilíbrio associado à progressão da DA. $O$ declínio da capacidade funcional não foi associado à maior ocorrência de quedas. $O$ déficit de equilíbrio não se correlacionou ao declínio funcional na DA.

Palavras-chave: doença de Alzheimer, equilíbrio, quedas, capacidade funcional, idosos.

\section{Correspondence \\ Eliane Mayumi Kato-Narita \\ Rua Rondinha 92 / 134 \\ 04140-010 São Paulo SP - Brasil \\ E-mail: elimkato@yahoo.com.br}

Received 2 April 2010

Received in final form 27 September 2010

Accepted 4 October 2010
Due to the growing number of elderlies, a worldwide observed phenomenon, there is an increase in chronic and degenerative diseases, which are responsible for impairment on physical abilities, quality of life worsening and emotional suffering, both of elderly and their caregivers.
Alzheimer's disease (AD), which is responsible for approximately $50-70 \%$ of all dementias, is extremely handicapping, causing impairment in cognitive function, functional capacity and behavior ${ }^{1,2}$. Many studies have reported such alterations and many research efforts have been 
spent aiming to slow the evolution of symptoms, and to avoid complications which might either worsen the disease or cause death ${ }^{3,4}$.

One of these undesirable changes is motor decline, which appears as apraxia, slowed movements, extrapiramidal signs, involuntary movements, and gait and balance disturbances, impairing movement planning and execution, and therefore the functional capacity. These symptoms vary according to the stage of the disease $\mathrm{e}^{5,6}$.

Body balance, an essential motor skill necessary to perform both static and dynamic everyday activities with stability and security, is impaired in AD when compared to cognitively preserved elderlies ${ }^{7}$.

AD patients present enhanced corporal swaying, especially with lack of visual information; restricted limits of stability; greater postural instability during doubletasks, such as walking and talking simultaneously; and reduction of balance strategies, necessary to prevent falls ${ }^{7-10}$.

Balance control is influenced by several factors, such as medications, which may cause drowsiness or vertigo; and by visual, vestibular or somatosensitive deficits that may impair postural reaction control ${ }^{10,11}$.

A consequence of balance impairment in $\mathrm{AD}$ is an increase in the probability of the occurrence of falls ${ }^{12,13}$. Falls are more frequent in AD than in non-demented elderlies, cause more fractures and deaths, increase time of hospitalization, and are responsible for most of institutionalizations ${ }^{12,14,15}$.

Falls prevalence in $\mathrm{AD}$ varies according to the stage of disease, given that in mild $\mathrm{AD}$ there is less motor impairment than in moderate $\mathrm{AD}^{13,16}$. However, attentional deficits are already present in mild $\mathrm{AD}$, which is a additional factor leading to falls in this population. Moderate $\mathrm{AD}$ patients are more dependent on their caregivers, and may suffer fewer falls due to constant supervision. Another implication of balance deficit is the decrease on mobility and functional capacity, due to fear of falls and consequent restriction of mobility.

The aim of this study is to verify the correlation between balance impairment, falls and reduction of functionality in $\mathrm{AD}$.

\section{METHOD}

\section{Participants}

All participants were 60 years and older, of both genders. Forty eight AD patients were recruited from an outpatient service at a university hospital. The AD diagnosis was based on NINCDS-ADRDA ${ }^{17}$ and patients were classified according to the Clinical Dementia Rating $(C D R)^{18}$ scale. Twenty five patients were classified as CDR 1 (mild AD) and twenty three as CDR 2 (moderate $\mathrm{AD}$ ). Forty elderlies without cognitive impairment were included as control group according to the Mayo Older American Normative Studies criteria ${ }^{19}$.

Participants were excluded if they had non-Alzheimer dementia or other neurological diseases; severe dementia (CDR higher than 2); limited mobility due to pain or amputation; presence of vertigo or dizziness; signs of vestibular syndrome; episodes of loss of consciousness; nontreated depression; visual impairment non-corrected by glasses; and severe hypoacusia.

Regarding medication intake, all AD patients were under treatment with anticholinerestase drugs. Fifteen patients and 3 controls were taking antidepressant drugs; 12 patients were taking antipsychotic medication; 5 controls were taking muscular relaxing drugs; 21 patients and 19 controls were under antihypertensive treatment; 3 controls were taking antiarritmics; 1 patient and 1 control were taking benzodiazepines.

All participants or their legal representatives signed an informed consent for enrollment in the study. This study was approved by the local Ethics Committee.

\section{Assessment}

All participants answered a questionnaire containing socio-demographic data, data concerning use of walkingaid, as well as history of falls in the past twelve months and its characteristics, as frequency, cause, period of occurrence during the day and consequences (functional limitation, fractures, hospitalization). Falls were described to caregivers as any event in which the elderly unintentionally came to rest on the floor or on a lower level from which he or she was standing, regardless of whether or not an injury was sustained.

Cognitive status was measured through the Mini Mental State Examination (MMSE) ${ }^{20}$. The presence of depressive symptoms in the AD group was assessed through the Cornell Depression Scale (CDS) ${ }^{21}$. Functional abilities were evaluated through the Disability Assessment for Dementia (DAD) questionnaire ${ }^{22}$, which assess activities according to three main domains: Initiative, Planning and Organization, and Effective Realization; however, in this study we only considered Effective Realization (DADer) for analysis, given that this subitem specifically evaluate if the subject is able or not to perform the motor action itself. Balance was assessed through the Berg Balance Scale (BBS) ${ }^{23,24}$, a widely applied instrument for balance research in the elderly. In the $\mathrm{BBS}$, the maximum score posssible is 56 , and the highest the score, the better the balance.

\section{Data analysis}

Descriptive statistics (mean, standard deviation, minimum and maximum values) was performed for demographic data and variables of interest (MMSE, 
CDS, DADer, BBS and number of falls). Comparison of means among the three groups (controls, mild and moderate AD) was performed using one-way ANOVA with Tukey's post-test. Student's t test for independent samples was employed to compare continuous variables between two groups (mild and moderate AD). The distribution of frequencies for categorical variables (gender, occurrence and recurrence of falls) was analyzed through the Chi-square test. The association between pairs of interest variables (number of falls, BBS and DADer scores) was tested through Pearson's correlation test. Analyses were conducted comparing "fallers" and "non fallers" subgroups, being "fallers" defined as subjects who had experienced at least one fall in the past twelve months. The level of significance adopted for all analyses was 0.05 .

\section{RESULTS}

Table 1 shows the demographic data of the sample. There were no diferences in age and schooling among the three groups. As expected, the control group performed better in the MMSE than AD patients. Mild (CDR 1) and moderate (CDR 2) patients did not differ in the CDS scores. There was a predominance of females in the $\mathrm{AD}$ group. Regarding medication intake, there was a significant difference between controls and AD patients for anticholinesterase $(\mathrm{p}<0.0001)$, antidepressive $(\mathrm{p}=0.02)$, antipsychotic ( $\mathrm{p}=0.0008)$, and muscular relaxing drugs $(p=0.039)$, but there were no differences between CDR 1 and CDR 2 patients.

Table 2 displays the scores obtained for the BBS. Moderate AD patients differed from controls in the BBS scores, that difference being observed in the total sample and in the non fallers groups. The comparison between fallers and non fallers did not disclose any further differences ( $\mathrm{p}=0.086$ for controls, 0.151 for CDR 1 patients and 0.932 for CDR 2 patients).

Table 3 shows the number and percentage of subjects that suffered falls (fallers subgroup) and the number of falls in the total sample and in the fallers subgroup, in the

Table 1. Demographic data of the sample.

\begin{tabular}{|c|c|c|c|c|c|c|}
\hline Variable & Controls & $A D$ (total) & CDR 1 & CDR 2 & $\mathrm{p}$ (two-tailed) & Multiple comparison \\
\hline \multirow[t]{2}{*}{ Age (yrs) } & $74.5(7.3)$ & $77(6.3)$ & $77(7)$ & $77(5.5)$ & \multirow{2}{*}{0.093} & \multirow{2}{*}{ NA } \\
\hline & $65-79$ & $65-88$ & $66-88$ & $65-87$ & & \\
\hline \multirow[t]{2}{*}{ Schooling (yrs) } & $6.6(4.8)$ & $5.5(5)$ & $5.5(5.3)$ & $5.5(4.7)$ & \multirow{2}{*}{0.316} & \multirow{2}{*}{ NA } \\
\hline & $0-20$ & $0-21$ & $0-21$ & $0-15$ & & \\
\hline \multirow[t]{2}{*}{ MMSE } & $26.8(3)$ & $16.2(5.1)$ & $18.6(3.9)$ & $13.6(5.1)$ & \multirow{2}{*}{$<0.001$} & \multirow{2}{*}{ All groups differ } \\
\hline & $19-30$ & $0-27$ & $11-27$ & $0-22$ & & \\
\hline \multirow[t]{2}{*}{ CDS } & \multirow[t]{2}{*}{ NA } & $3.4(2.7)$ & $2.9(2.7)$ & $4(2.7)$ & \multirow{2}{*}{0.179} & \multirow{2}{*}{ NA } \\
\hline & & $0-12$ & $0-12$ & $1-11$ & & \\
\hline \multicolumn{7}{|l|}{ Gender (n, \%) } \\
\hline M & $18(45 \%)$ & $14(29 \%)$ & $9(36 \%)$ & $5(22 \%)$ & \multirow{2}{*}{$C G \neq A D$} & \multirow{2}{*}{0.006} \\
\hline $\mathrm{F}$ & $22(55 \%)$ & 34 (71\%) & $16(64 \%)$ & 18 (78\%) & & \\
\hline
\end{tabular}

Results are displayed as M (SD) Range, except for gender; NA: not applied.

Table 2. Performance of the sample and intergroup comparison for Berg Balance Scale,

\begin{tabular}{lcccccc}
\hline Group & Controls & AD (total) & CDR 1 & CDR 2 & p (two-tailed) & Multiple comparison \\
\hline Total sample & $53.1(2.9)$ & $51.3(3.1)$ & $51.8(3.1)$ & $50.7(3)$ & 0.001 & CDR 0 $\neq$ CDR 2 \\
& $46-56$ & $43-56$ & $43-56$ & $44-56$ & & \\
Fallers & $52.2(3)$ & $50.8(3.2)$ & $50.9(3.4)$ & $50.6(2.9)$ & & NA \\
& $46-56$ & $43-56$ & $43-56$ & $44-55$ & & \\
Non fallers & $53.8(2.6)$ & $51.7(3)$ & $52.7(2.6)$ & $50.7(3.3)$ & & 0.015 \\
& $47-56$ & $44-56$ & $47-56$ & $44-56$ & CDR 0 $\neq$ CDR 2 \\
\hline
\end{tabular}

Results are displayed as M (SD) Range; NA: not applied. 
Table 3. Number of falls and percentage of subjects that suffered falls in the past twelve months.

\begin{tabular}{|c|c|c|c|c|c|}
\hline Variable & Controls & $A D$ & CDR 1 & CDR 2 & $\mathrm{p}$ (two-tailed) \\
\hline \multicolumn{6}{|l|}{ Number of falls } \\
\hline \multirow[t]{2}{*}{ Total sample } & $0.6(0.9)$ & $0.9(1.2)$ & $1.2(1.5)$ & $0.6(0.8)$ & \multirow{2}{*}{0.415} \\
\hline & $0-3$ & $0-6$ & $0-6$ & $0-3$ & \\
\hline \multirow[t]{2}{*}{ Fallers } & $1.4(0.8)$ & $1.7(1.2)$ & $2(1.52)$ & $1.3(0.6)$ & \multirow{2}{*}{0.662} \\
\hline & $1-3$ & $1-6$ & $1-6$ & $1-3$ & \\
\hline $\begin{array}{l}\text { Occurrence of falls } \\
\text { (number of subjects, \%) }\end{array}$ & $18(45 \%)$ & $24(50 \%)$ & 13 (52\%) & $11(47.8 \%)$ & 0.772 \\
\hline $\begin{array}{l}\text { Reccurrence of falls } \\
\text { (number of subjects, \%) }\end{array}$ & $5(12.5 \%)$ & $9(18.7 \%)$ & $6(25 \%)$ & $3(14.3 \%)$ & 0.617 \\
\hline
\end{tabular}

Results are displayed as M (SD) Range.

Table 4. Performance of the sample and intergroup comparison for effective realization.

\begin{tabular}{lcccccc}
\hline Group & Controls & AD & CDR 1 & CDR 2 & p (two-tailed) & Multiple comparison \\
\hline Total sample & $100(0)$ & $73.1(17.8)$ & $80.9(13.8)$ & $64.6(18)$ & $<0.0001$ & CDR 0 F CDR 1 and CDR 2 \\
& & $17.6-100$ & $46.6-100$ & $17.6-100$ & & All groups differ \\
Fallers & $100(0)$ & $74.8(18.1)$ & $80.9(15.4)$ & $67.5(19)$ & $<0.0001$ & All groups differ \\
& & $35.3-100$ & $46.6-100$ & $35.3-100$ & & \\
Non fallers & $100(0)$ & $71.4(17.6)$ & $80.9(12.5)$ & $62(17.4)$ & & $<0.0001$ \\
\end{tabular}

Results are displayed as M (SD) Range.

past twelve months. There were no difference in the incidence of falls among the three groups.

Table 4 shows the results for DAD Effective Realization for all groups. The control group differed from $\mathrm{AD}$ patients (CDR 1 and 2) in the DAD Effective Realization scores. There were no differences in performance between fallers and non fallers ( $\mathrm{p}=1$ for controls, 0.518 for CDR 1 patients and 0.887 for CDR 2 patients).

We found a negative correlation between the number of falls and the scores on the BBS in the control group $(r=-0.383 ; p=0.015)$. In the fallers subgroup, we found a negative correlation between the number of falls and BBS scores in the moderate AD group ( $r=-0.613 ; \mathrm{p}=0.045)$.

\section{DISCUSSION}

In the present study, we did not found difference on balance in mild AD when compared to controls. Such difference was found only in the moderate stage of the disease. The same results were described by O'Keeffe et $\mathrm{al}^{25}$ in an analysis of balance and gait in $\mathrm{AD}$ through the Tinetti test, where they encountered dysfunction in balance in $36 \%$ of controls, $43 \%$ of mild AD, $60 \%$ of moderate $\mathrm{AD}$, and $79 \%$ of severe $\mathrm{AD}$. In our study, the fallers group achieved lower (although not statistically different) scores in the BBS, except for the moderate AD patients. Moderate $\mathrm{AD}$ patients had similar scores in the BBS regardless of being fallers or non fallers, but in the non fallers subgroup, moderate AD patients achieved lower BBS scores than controls and mild AD patients.

However, we did not find any differences in the incidence of falls among the groups. This might be due to a slightly higher frequency of falls in our control group than that described in other community-dwelling studies (approximately $30 \%)^{26,27}$. This may also reflect the fact that balance dysfunction occurring in AD patients that do not present parkinsonism, vestibular signs or other motor abnormalities may not be severe enough as to determine a higher incidence of falls, in the absence of other risks factors. Another factor that may explain the non increase in the frequency of falls in the moderate $\mathrm{AD}$ group, despite the balance impairment, is that these patients tend to be subject to mobility restriction imposed by their caregivers, and also by the patient's fear of falling, as observed by Fitzgerald et al. ${ }^{28}$.

According to many systematic reviews ${ }^{29-31}$, falls in dementia have no defined risk factors, because they are 
multifactorial, and depend on many conditions, as the use of drugs, environmental risks, caregivers' level of attention, severity of the disease, presence of parkinsonism signs, behavioural changes and others. Patients enrolled in this study were specifically selected in order to control for the confounding factors related to motor and balance abnormalities, since most studies in the literature were conducted in mixed samples including patients with concurrent Parkinson's disease, cerebrovascular disease, and dementias of other etiologies, and did not have inclusion criteria as restrictive as the present study $y^{5,12,14,15,31,32}$.

A moderate and negative correlation was found on the fallers subgroup between number of falls and BBS score, showing that motor impairment, assessed by balance, contributes to reccurrence of falls. Moreover, $45 \%$ of controls have fallen at least once in the last twelve months, but no correlation was found between the number of falls and scores in BBS. A detailed analysis of causes of fall in this subgroup of normal elderly showed that the main reasons for falling were: environmental risks (as public transportation), presence of pets in the subject's home, behavioural risk factors (as climbing stairs or in chairs in order to reach high places such as cabinets), and use of drugs ${ }^{10}$ commonly related to falls (data not shown), as cited by Eriksson et al. ${ }^{29}$. For more detailed information about falls in AD see Kato-Narita and Radanovic, $2009^{16}$.

One of the hypothesis of our study was that loss of functional capacity might be associated to balance deficits and occurrence of falls, as discuted by Holmes \& Lovestone ${ }^{33}$, and by Fitzgerald et al. $^{28}$. However, although a decline in functional capacity according to DADer scores have been observed in both stages of $\mathrm{AD}$, we found association between functional disability and lower BBS scores only in mild AD (in the fallers subgroup). This suggests that mild impairments in balance are not suffcient to determine functional impairment in normal elderly, but may be considered as a risk factor for functional impairment as the diseases progresses, due to the consequent restriction of mobility, especially when the subject is prone to falls.

Our results show that the balance impairment, occurrence of falls and functional impairment do not obey a direct and straight cause-effect relationship. Several risk factors interact in order to determine whether or when AD patients will begin to have a higher incidence of falls, and this may not happen to all patients. We were able to demonstrate in this study that balance impairment is not a prominent finding in $\mathrm{AD}$ in the absence of other conditions such as extrapyramidal and vestibular signs, or muscular deficits, and that there seems not to exist a strict correlation between balance impairment, occurrence of falls and functional abilities, as mea- sured through DAD. These findings may have implications in rehabilitation efforts, suggesting that different approaches must be used to prevent falls and to restore functional abilities, not assuming that improving one skill (balance) will necessarily ameliorate the others (occurrence of falls and functionality). As a general rule, it is advisable to avoid mobility restriction, as it might worsen the motor impairment associated to the disease, as well as strenght and balance, and be a risk for falls, injuries and progression of the disease.

A limitation of this study is the small number of subjects in each CDR subgroup, and in the fallers subgroup. To the best of our knowledge, this is the first study to address the interrelation among balance impairment, occurrence of falls and functional capacity exclusively on $\mathrm{AD}$ patients subdivided by disease severity.

\section{REFERENCES}

1. Alzheimer's Association. 2008 Alzheimer's disease facts and figures. Alzheimers Dement 2008;4:110-113.

2. Ferri CP, Prince $M$, Brayne $C$, et al. Global prevalence of dementia: a Delphi consensus study. Lancet 2005;366:2112-2117.

3. Heyn P, Abreu BC, Ottembacher KJ. The effects of exercise training on elderly persons with cognitive impairment and dementia: a meta-analysis. Arch Phys Med Rehabil 2004;85:1694-1704.

4. Papp KV, Walsh SJ, Snyder PJ. Immediate and delayed effects of cognitive interventions in healthy elderly: a review of current literature and future directions. Alzheimers Dement 2009;5:50-60.

5. Waite LM, Broe GA, Grayson DA, Creasey H. Motor function and disability in the dementias. Int J Geriatr Psychiatry 2000;15:897-903.

6. Pettersson AF, Olsson E, Wahlund LO. Motor function in subjects with mild cognitive impairment and early Alzheimer's disease. Dement Geriatr Cogn Disord 2005;19:299-304.

7. Pettersson AF, Engardt M, Wahlund LO. Activity level and balance in subjects with mild Alzheimer's disease. Dement Geriatr Cogn Disord 2002;13: 213-216.

8. Waite LM, Broe GA, Grayson DA, Creasey H. Motor function and disability in the dementias. Int J Geriatr Psychiatry 2000;15:897-903.

9. Chong RK, Horak FB, Frank J, Kaye J. Sensory organization for balance: specific deficits in Alzheimer's disease but not in Parkinson's diasease. J Gerontol A Biol Sci Med Sci 1999;54:122-128.

10. Leipzig RM, Cumming RG, Tinetti ME. Drugs and falls in older people: a systematic review and meta-analysis I. Psychotropic drugs. J Am Geriatr Soc 1999:41:30-39.

11. Kallin K, Gustafson Y, Snadman PO, Karlsson S. Factors associated with falls among elderly, cognitively impaired people in geriatric care settings: a population-based study. Am J Geriatr Psychiatry 2005;13:1-9.

12. van Doorn C, Gruber-Baldini AL, Zimmermann S, et al. Dementia as a risk factor for falls and fall injuries among nursing home residents. J Am Geriatr Soc 2003;51:1213-1218.

13. Camicioli R, Licis L. Motor impairment predicts falls in specialized Alzheimer care units. Alzheimer Dis Assoc Disord 2004;214-218.

14. Asada T, Kariya T, Kinoshita T, et al. Predictors of fall-related injuries among community-dwelling elderly people with dementia. Age Aging 1996; 25:22-28.

15. Shaw FE. Falls in older people with dementia. Geriatr aging 2003;6:37-40.

16. Kato-Narita EM, Radanovic M. Characteristics of falls in mild and moderate Alzheimer's Disease. Dementia Neuropsychol 2009;3:337-343.

17. Mckhann G, Drachman D, Folstein M, Katzman R, Price D, Stadlan EM. Clinical diagnosis of Alzheimer's disease: report of the NINCDS-ADRDA work group under the auspices of the Department of Health an Human Services Task Force on Alzheimer's Disease. Neurology 1984;34:939-944.

18. Morris JC. Clinical Dementia Rating: a reliable and valid diagnostic and staging measure for dementia of the Alzheimer type. Int Psychogeriatr 1997;9:173-176. 
19. Smith GE, Ivnik RJ. Normative neuropsychology. In: Petersen RC (Eds). Mild cognitive impairment. New York: Oxford 2003;63-88.

20. Folstein MF, Folstein SE, Mchugh PR. The Mini-Mental State: a practical method for grading the cognitive state of patientes for the clinician. J Psychiatr Res 1975;12:189-198.

21. Alexopoulos GS, Abrans RC, Young RC, Shamoian CA. Cornell Scale for Depression in Dementia. Biol Psychiatry 1988;23:271-284.

22. Gélinas I, Gauthier L, Mcintyre M, Gauthier S. Development of a functional measure for persons with Alzheimer's disease: the disability assessment for dementia. Am J Occup Ther 1999;53:471-481.

23. Berg K, Wood-Dauphinée S, Williams Jl, Maki, B. Measuring balance in the elderly: validation of an instrument. Can J Public Health 1992;83 (Suppl):S71.

24. Miyamoto ST, Junior IL, Berg KO, Ramos LR, Natour J. Brazilian version of the Berg Balance Scale. Braz J Med Biol Res 2004;37:1411-1421.

25. O'Keeffe ST, Kazeen H, Philpott RM, Playfer JR, Gosney M, Lye M. Gait disturbance in Alzheimer's disease: a clinical study. Age Ageing 1996;25: 313-316.

26. Pinheiro MM, Ciconelli RM, Martini LA, Ferraz MA. Risk factors for reccurrent falls among brazilian women and men: the Brazilian Osteoporosis Study (BRAZOS). Cad Saúde Pública 2010;26:89-96.
27. Cesari M, Landi F, Onder G, Lattanzio F, Bernabei R. Prevalence and risk factors for falls in an older community-dweeling population. J Gerontol 2002;57:722-726

28. Fitzgerald TG, Hadjistavropoulos T, MacNab YC. Caregiver fear of falling and functional ability among seniors residing in long-term care facilities. Gerontology 2009;55:460-467.

29. Eriksson S, Gustafson Y, Lundin-Olsson L. Risk factors for falls in people with and without a diagnose of dementia living in residential care facilities: a prospective review. Arch Gerontol Geriatrics 2008;46:293-306.

30. Härlein J, Dassen T, Halfens RJ, Heinze C. Fall risk factors in older people with dementia or cognitive impairment: a systematic review. J Adv Nurs 2009;65:922-933.

31. Allan LM, Ballard CG, Rowan EN, Kenny RA. Incidence and prediction of falls in dementia: a prospective study in older people. Plos One 2009;4:5521-5528.

32. Pelfolk T, Gustafsson T, Gustafsson Y, Larlsson S. Risk factors for falls among residents with dementia living in group dwelling. Int Psychogeriatr 2009;21:187-194.

33. Holmes C, Lovestone S. Long-term cognitive and functional decline in late onset Alzheimer's disease: therapeutic implications. Age aging 2003;32: 200-204. 